\title{
3D FEM to predict residual stresses of press-braked thin-walled steel sections
}

\begin{abstract}
Cold-formed steel sections are normally produced by cold work manufacturing processes. The amount of cold work to form the sections may have induced residual stresses in the section especially in the area of bending. Hence, these cold work processes may have significant effects on the section behaviour and load-bearing capacity. There was a lack of studies in investigating the effects of residual stresses raised by press-braking operations unlike the roll-forming operation. Therefore, a 3D finite element simulation was employed to simulate this forming process. This study investigated the magnitude of the maximum residual stresses along the length of the corner region and through-thickness residual stress variations induced by the press-braking forming process. The study concluded that residual stresses are not linear longitudinally (along the corner region). Maximum residual stresses exist near the middle surface of the plate. The comparison of the 3D-FE results with the 2DFE results illustrate that 3D-FE has a variation in transverse and longitudinal residual stresses along the plate length. In addition, 2D-FE results overestimate the residual stresses along the corner region.
\end{abstract}

Keyword: Cold-formed steel; FEM; Residual stresses 